\title{
Continuity of care for carers of people with severe mental illness: results of a longitudinal study
}

Article

Accepted Version

Burns, T., Catty, J., Harvey, K., White, S., Rees Jones, I., McLaren, S. and Wykes, T. (2013) Continuity of care for carers of people with severe mental illness: results of a longitudinal study. International Journal of Social Psychiatry, 59 (7). pp. 663-670. ISSN 1741-2854 doi:

https://doi.org/10.1177/0020764012450996 Available at https://centaur.reading.ac.uk/31109/

It is advisable to refer to the publisher's version if you intend to cite from the work. See Guidance on citing.

To link to this article DOI: http://dx.doi.org/10.1177/0020764012450996

Publisher: Sage

All outputs in CentAUR are protected by Intellectual Property Rights law, including copyright law. Copyright and IPR is retained by the creators or other copyright holders. Terms and conditions for use of this material are defined in the End User Agreement. 


\section{CentAUR}

Central Archive at the University of Reading

Reading's research outputs online 
Continuity of care in mental health: understanding and measuring a complex phenomenon

Short title: measuring continuity of care

Tom Burns ${ }^{1}$, Jocelyn Catty, Sarah White, Sarah Clement, Gemma Ellis, Ian Rees Jones, Pascale Lissouba, Susan McLaren, Diana Rose, Til Wykes for the ECHO Group

\section{The ECHO Group:}

Main Phase: Tom Burns ${ }^{1,2}$, Jocelyn Catty ${ }^{1,2}$, Sarah Clement ${ }^{3}$, Kate Harvey ${ }^{4}$, Sarah White ${ }^{1}$, Tamara Anderson ${ }^{1}$, Naomi Cowan ${ }^{1}$, Gemma Ellis ${ }^{1}$, Helen Eracleous ${ }^{1}$, Connie Geyer ${ }^{1}$, Pascale Lissouba $^{1}$, Zoe Poole ${ }^{1}$;

Qualitative Strand: Ian Rees Jones ${ }^{5}$, Nilufar Ahmed ${ }^{1}$;

Developmental Phase: Diana Rose ${ }^{6}$, Til Wykes ${ }^{6}$, Angela Sweeney ${ }^{6}$;

Organisational Strand: Susan McLaren ${ }^{3}$, Ruth Belling ${ }^{3}$, Jonathon Davies ${ }^{3}$, Ferew Lemma ${ }^{3}$, Margaret Whittock ${ }^{3}$.

1. For correspondence: Department of Psychiatry, University of Oxford, Warneford Hospital, Oxford OX3 7JX. Tel: + 44 (0)1865 226474. < tom.burns@psych.ox.ac.uk>

2. St. George's, University of London.

3. London South Bank University.

4. University of Reading.

5. University of Wales, Bangor

6. Institute of Psychiatry, London.

Word count: 2,973 


\begin{abstract}
Background

Continuity of care is considered by patients and clinicians an essential feature of good quality care in long-term disorders, yet there is general agreement that it is a complex concept. Most policies emphasise it and encourage systems to promote it. Despite this there is no accepted definition or measure against which to test policies or interventions designed to improve continuity. We aimed to operationalise a multi-axial model of continuity of care and to use factor analysis to determine its validity for severe mental illness.
\end{abstract}

\title{
Methods
}

A multi-axial model of continuity of care comprising eight facets was operationalised for quantitative data collection from mental health service users using 32 variables. Of these variables, 22 were subsequently entered into a factor analysis as independent components, using data from a clinical population considered to require long-term consistent care.

\section{Results}

Factor analysis produced seven independent continuity factors accounting for $62.5 \%$ of the total variance. These factors, Experience \& Relationship, Regularity, Meeting Needs, Consolidation, Managed Transitions, Care Coordination and Supported Living, were close though not identical to the original theoretical model.

\section{Conclusions}

We confirmed that continuity of care is multi-factorial. Our seven factors are intuitively meaningful and appear to work in mental health. These factors should be used as a starting-point in research into the determinants and outcomes of continuity of care in long-term disorders.

Conflict of interest: none 
Continuity of care is considered a corner-stone in the effective management of long-term disorders by service users, clinicians and healthcare policy-makers. It is fundamental in several policy documents (Department of Health 1990; Department of Health 1995; Department of Health 2001) and has been proposed as a useful criterion for mental health service evaluation (Johnson et al. 1997). The weight given it is reflected in the widespread use of case management (Mueser et al. 1998) and national policies such as the Care Programme Approach (CPA) in the United Kingdom (Department of Health 1990). Indeed, Tessler (1987) argues that it has replaced dependency and deinstitutionalisation as the central issue in service provision.

Yet while the importance of continuity of care has long been recognised, including for those with severe mental illness, it is generally agreed that there have been few attempts until recently to define it systematically, continuity being 'often lauded but seldom defined' (Freeman et al. 2000; see also Crawford et al. 2004). Definitions are frequently inadequate, often with only one or two elements included (Freeman et al. 2000). Freeman and colleagues (2000) identified 32 continuity of care studies in mental health and 14 in primary care but found more than ten definitions and few attempts to explicate and analyse the idea substantively. Crawford and colleagues (Crawford et al. 2004) reviewed 435 relevant papers, most of which did not define continuity of care. Haggerty and colleagues (2003), however, emphasise that without clear definitions of continuity of care it is possible neither to investigate nor to solve discontinuities.

Adair and colleagues (2003), charting the definitions of continuity of care over thirty years, found that continuity was rarely distinguished from the interventions themselves until the 1980s, when the idea that it might be a multidimensional concept began to emerge (Bachrach 1981), while in the 1990s continuity became seen as a potential measure of system-level reform. Where continuity had previously been seen as indicating care by the same caregiver or group of caregivers, the idea of continuity as involving the coordination of the patient's progress through the system gained hold.

Operationalising the concept of continuity of care, however, has been notoriously difficult. Many of the earlier studies focused on discharge after an acute care episode rather than on longitudinal changes in continuity (Adair et al. 2003) and this has been the case even in some recent studies which have successfully distinguished between the continuity after discharge achieved by different mental health systems (Sytema et al. 1997; Sytema \& Burgess, 1999). Sytema and colleagues (1997), however, also focused on flexibility of care, operationalised as the combinations of in-, day- and out-patient care used during follow-up, while other studies 
have focused on cross-boundary continuity between primary and secondary care (Bindman et al. 1997), psychiatric and emergency services (Heslop et al. 2000), or inpatient and community settings (Kopelowicz et al. 1998).

Several groups have proposed a range of conceptualisations which emphasise differing features: 'a sustained patient-physician partnership' (Nutting et al. 2003); maintenance of contact, consistency in the member of staff seen and success of transfer between services (Johnson et al.1997); and 'adequate access to care... good interpersonal skills, good information flow and uptake between providers and organizations, and good care coordination' (Reid et al. 2002), while discontinuity has been defined as gaps in care (Cook et al. 2000). Others have again emphasised that continuity of care be understood as multidimensional. Crawford and colleagues (2004) propose five factors based on sustained contact with services, breaks in service delivery, the same member of staff being seen, coordination of health and social professionals and the experience of care; Johnson and colleagues (1997) include maintenance of contact, consistency in the member of staff seen, transition and integration between services, adherence to service plans, and management of service users' needs; and Ware and colleagues (2003) utilise five domains: knowledge, flexibility, availability, coordination and transitions. Joyce and colleagues' (2004) systematic literature review found that continuity of care has been defined in terms of service delivery, accessibility, relationship base and individualized care.

The impact of continuity of care as a multidimensional concept on health and social outcomes has been less often studied, as studies have tended to either to examine outcomes with implications for continuity (such as loss of contact) or to examine interventions assumed to promote continuity (Freeman et al. 2000). Adair and colleagues (2005), however, found that better overall continuity, as a combined rating of a range of dimensions, was associated with better quality of life, better community functioning, lower symptom severity and greater service satisfaction, as well as with lower hospital costs and higher community costs (Mitton et al. 2005), although the direction of effects could not be determined.

Freeman and colleagues (2000) rated continuity of care studies from the service users' viewpoint according to relevance, method and concept and highlighted the necessity not only for clarity in the conceptualisation of continuity of care in order to be able to gauge its impact, but also for the inclusion of the service user's perspective. They summarise the principal characteristics of continuity of care in a 'multi-axial definition' comprising: experienced, crossboundary, flexible, information, relational and longitudinal. In a subsequent study of continuity 
in mental health settings (Freeman et al. 2002), they added two further definitions, contextual and long-term. This extended model was the starting-point for the present study. (See Box 1.)

- Box 1 about here-

\begin{abstract}
Aims
We aimed to test whether a multi-factorial model of continuity of care could be operationalised for users of mental health services and whether systematically collected service user-level data would confirm the model's validity for this group.
\end{abstract}

\title{
Methods
}

\section{Sample and procedure}

People with long-term psychotic disorders were sampled from the caseloads of seven Community Mental Health Teams (CMHTs) covered by two mental health Trusts. The inclusion criteria were: clinical diagnosis of any psychotic disorder received at least two years previously, on the caseload of the CMHT for at least six months and aged 18 to 65. Diagnosis was confirmed by use of OPCRIT (McGuffin et al. 1991).

Freeman and colleagues' $(2002 ; 2002)$ multi-axial model of continuity of care was taken as the starting-point. Each of its eight facets or definitions was operationalised by identifying data and/or measures which approximated to it. The variables used to operationalise each definition were agreed by expert consensus within the multidisciplinary research group. They were chosen for their closeness to the definition being considered, the likelihood and regularity of their being recorded in the case notes or the availability of established, validated instruments for obtaining them during a single interview.

Interviews collected basic data on: patterns of contact with services in the preceding 12 months; breaks in care; and referrals to other services including hospital admission. Demographic and illness data were also collected. Three questionnaire measures were also completed. The Camberwell Assessment of Need (CAN) (Phelan et al. 1995) was used in the operationalisation of flexible continuity and the Scale to Assess Therapeutic Relationships in Community Mental Health Care - service user version (STAR) (McGuire-Snieckus et al. 2006) was used in the operationalisation of relational continuity. CONTINU-UM (Rose et al. submitted), a usergenerated measure of continuity developed for the study, was utilised as a proxy for experienced continuity. Data on contact with services, number of professionals seen and information flow 
were also collected from CMHT records by study researchers using a standard schedule developed for the study. This recorded every face-to-face and telephone contact made between team and the user; the discipline of the professional involved; for every transition in care (referral to an alternative or additional service, including admission to inpatient care), its date and whether appropriate documentation was recorded as having been sent or received; whether the annual CPA documentation was recorded as having been sent to the user, their carer and their GP; and contact between the CMHT and the GP.

\section{Analysis}

The continuity components were manipulated in order to give them comparable weight. Continuous variables were $\mathrm{z}$-scored if normally distributed or otherwise converted into categorical variables. Variables were coded so that a positive score indicated an assumed positive scenario. The direction of relationships as determined by the factor analysis, however, would indicate the final direction of the variables. Variables were omitted from further analysis if there was insufficient spread of response (less than 5\% in any category) or if two variables had a Spearman Rank correlation coefficient of 0.8 or more, in which case one was omitted.

Bartlett's test of sphericity and the Kaiser-Meyer-Olkin (KMO) measure of sampling adequacy (Kaiser 1974) were used to evaluate the strength of the linear association between the items in the inter-item correlation matrix. Variables were omitted if their individual measure of sampling adequacy was unacceptably low, until the overall KMO measure of sampling adequacy reached an acceptable level.

Exploratory factor analysis was carried out on variables retained after preliminary screening. A Principal Component Analysis was used to extract factors with an eigenvalue greater than one. A Varimax rotation was then used to produce interpretable independent factors. Extracted factors were interpreted by identifying the items which loaded onto each with a rotated factor loading of over 0.5. Analyses were conducted in SPSS v.14 for Windows.

\section{Results}

\section{Sample}

Initially, 609 service users were identified as being potentially eligible for the study. Of these, 111 did not meet the inclusion criteria and 318 declined to participate, leaving 180 service users 
to be interviewed. Characteristics of the sample are given in Table 1. The diagnosis of psychosis was confirmed by OPCRIT (McGuffin et al. 1991) for 171.

- Tables 1 about here -

- Box 2 about here -

\section{Operationalising continuity of care}

Freeman's eight definitions of continuity were operationalised using a total of 32 components for consideration for entry into the factor analysis (Box 2).

Experienced continuity: our over-arching concept for the purposes of this study (and therefore not necessarily interpreted as either 'coordinated' or 'smooth'), this was to capture the service user perspective and operationalised using CONTINU-UM.

Flexible continuity: conceptualised as the range of needs at any single time-point being met, this was operationalised using $\mathrm{CAN}$ and as response to change in clinical needs over time as increased rate of contacts in the three months prior to any hospital admission or service userreported deterioration.

Cross-boundary continuity: conceptualised as transitions and fragmentations, this was operationalised as referrals to other services, admissions to hospital, discharges from hospital, number of agencies involved and any user-reported contact with primary care.

Continuity of information: determined by the number of transitions collected for cross-boundary continuity, this was operationalised as a) documents sent as a proportion of the identified transitions b) proportion of letters copied or sent directly to the user; c) number of people to whom CPA documentation was copied (an established good-practice requirement for long-term care in this group).

Longitudinal continuity: this was operationalised as a) any change in who acts as the user's care coordinator and the number of staff in that role; b) any change in who acts as the user's psychiatrist and the number of psychiatrists in that role; c) 'spread of non-medical CMHT input' (number of different non-medical team members seen out of the total number of contacts with non-medical team members) and d) 'spread of medical CMHT input' (number of different medical team members seen out of the total number of contacts with medical team members). 
Relational or personal continuity: this was operationalised as the user-rated STAR.

Long-term continuity: interpreted as breaks in care and user-initiated discontinuity, this was operationalised as: user-reported level of attendance of appointments with CMHT; number of user-initiated breaks from mental health care reported by user; user-reported medication adherence; total number of CMHT contacts in year; longest gap between contacts with secondary care team; number of gaps of more than two months; number of more than average gaps (quantified as user's individual mean gap $* 2+2$ weeks); number of days between hospital discharge and face-to-face contact with a member of the CMHT.

Contextual continuity: interpreted as social context, this was operationalised as living situation (supported accommodation or independent) and daily activities (day care).

When the inter-item correlation matrix was constructed, ten components were omitted from further analysis. 'Total number of phone calls' was omitted due to inconsistent case note recording. The variables 'Saw known CMHT member when hospitalised' , 'Increased contacts in three months prior to user deterioration', 'Increased contacts in three months prior to admission' and 'Number of user-rated breaks in care' were omitted due to insufficient spread of response. 'Total number of face-to-face contacts' was found to be correlated with 'average gap between face-to-face contacts' $(\mathrm{r}=0.88)$ and was therefore omitted from further analysis. 'Longest gap between face-to-face contacts' was highly correlated with 'average gap between face-to-face contacts' $(\mathrm{r}=0.86)$ and 'gap of two months or more' $(\mathrm{r}=0.86)$, so was omitted. 'Referred to other agency' was highly correlated with 'had a transition' ( $r=0.81)$ and so was omitted. 'Number of unmet needs' was highly correlated with 'proportion of needs met' $(r=0.94)$ so it was omitted, while 'CAN total number of needs' was highly correlated with 'CAN total level of need' ( $r=0.93$ ) and was thus omitted. Thus 22 components were appropriate for entry into the exploratory factor analysis.

\section{Factor analysis}

A factor analysis was conducted to explore how the different components of continuity relate to each other. Entering the 22 components produced a KMO statistic of 0.49 , just below the 0.5 threshold of an acceptable measure of sampling adequacy (Kaiser, 1974). The individual measures of sampling adequacy were then examined and two were found to be very low so removed from the factor analysis: 'gaps of (average gap* $2+2$ weeks)' $(0.28)$ and 'medical input spread' $(0.22)$. In the repeated factor analysis, Bartlett's test of sphericity indicated that the 
correlation matrix was not an identity matrix $\left(\chi^{2}=540.5, \mathrm{p}<0.001\right)$. The KMO measure of sampling adequacy was 0.54 , which while still low was acceptable. (The correlation matrix is not presented but is available from the first author on request.) Seven factors were extracted with an eigen value of one or more, explaining $62.5 \%$ of the total variance in the data (Table 2). Where the factor was predominately characterised by a component or components used to operationalise the original multi-axial model, the name of that definition is added in parentheses in Table 2. Factor 5, Managed Transitions, was recoded into a straightforward trichotomous variable.

The majority of components loaded significantly onto one factor only, with rotated loadings of 0.5 and above. There were four exceptions to this. 'Any user-rated breaks in care?', 'CPA copied to GP and user?', 'number of care coordinators in the past year' and 'attended a day centre' all had absolute loadings between 0.4 and 0.5 onto only one factor so were allocated to that respective factor.

Summary statistics for the 20 components of continuity of care in the seven-factor model are presented in Table 3.

- Tables 2 and 3 about here-

\section{Discussion}

This study was based on the premise that continuity of care is 'often lauded but seldom defined' (Freeman et al. 2000). Anecdotal evidence would suggest that professionals tend to recognise the idea of continuity of care and intuitively accept it as a worthy goal, despite the paucity of evidence about what it means in practice.

We operationalised the original model to enable its systematic measurement and exploration using quantitative service user-level data. We used the global score of the new measure, CONTINU-UM, as a proxy for experienced continuity (as an overarching concept), treating it as a single measure that would reflect participants' own experiences and perspectives on the continuity of care they received. We operationalised the remaining elements utilising multiple components (collected both through interview and from clinical records) that, between them, would reflect the full range of concepts covered by the multi-axial model from which we started. By exploring the relationships between these components through a factor analysis, we found them to be grouped differently in practice, providing a new seven-factor model 
comprising Experience \& Relationship, Regularity, Meeting Needs, Consolidation, Managed Transitions, Care Coordination and Supported Living. These have clear relationships with the different elements of Freeman and colleagues' model, although they are not synonymous.

Our methodology was comparable to that of Adair and colleagues (2003), whose measure developed for the Canadian context includes both patient- and observer-rated scales. Our factors Experience \& Relationship and Meeting Needs partially matched their patient-rated sub-scales 'relationship base' and 'responsive treatment' respectively, while their other sub-scale 'system fragmentation' seems to have been reflected in our analysis by three distinct factors, Consolidation, Managed Transitions and Care Coordination.

Our analysis thus confirms Freeman and colleagues' argument and Adair and colleagues' finding that continuity of care comprises more than one single entity. The overarching concept of continuity of care can be broken down into a number of independent concepts and the factors that emerged from our analysis seem intuitively meaningful and practical.

\section{Methodological issues}

The conclusions of this paper are inevitably derived from a sample who agreed to take part. How this group may have contrasted with the larger group who refused is unknown. It is possible, though not proven, that those who refused may have been less well engaged with or favourably disposed towards services. If this were the case, this would be likely to affect the levels of several of the continuity factors of the sample (such as Experience \& Relationship or Regularity), rather than affecting the overall factor structure.

We took an inclusive approach to operationalising and measuring the original model. Consistently with this, we did not remove items from the Exploratory Factor Analysis which were weakly correlated with each other $(<0.3$ as is sometimes advised), as it was quite possible that different components of continuity would be unrelated to each other.

Given the nature of some of the components included, it was likely that some of them would not be related to each other, affecting the KMO-statistic (measuring sampling adequacy). Overall measures of good fit may, therefore, not be applicable to our aims.

Data from records were limited by the availability of the information on file. This may have varied between CMHTs. In assessing information continuity and its related components, 
whether the requisite information was on file was highly relevant. We therefore worked on the assumption that information not on file had not been sent, a conservative estimation of information flow. It is possible that the accuracy of service contact or transitions data may have been compromised by the quality of case-notes in a way that could not be quantified and which may have varied between CMHTs.

While the factors are intuitively meaningful, their scoring is not and this complicates interpretation, which needs to be based on the components loading onto each factor.

\section{Potential use of these factors}

Our factor structure is helpful in challenging preconceptions about likely correlates of care practices. For instance, care components linked with Care Coordination and those linked with Experience \& Relationship loaded onto separate factors, suggesting that focusing care on a single care coordinator is no guarantee in itself of better relational or experienced continuity. The loading of 'designated psychiatrist' onto Care Coordination suggested this was common and reflected a choice in provision of care: users were more likely to see no psychiatrist or more than two (that is, to have no particular psychiatrist relating to them) if they saw only one or two care coordinators. This suggests that teams were choosing between emphasising continuity achieved through the care co-ordinator or through the psychiatrist, without any evidence of this being based on an explicit policy. Any assumption that the one smoothly substitutes for the other is challenged by service users' reports in in-depth interviews conducted in a related study (Jones, personal communication), which found that they disliked having to see several psychiatrists, even if they had a single care coordinator.

Johnson and colleagues (1997) proposed that continuity be used as an important quality measure for services, but until recently there have been no metrics. Our operationalisation of Freeman and colleagues' original model draws on routinely collected data and well-known and validated measures. Our factors may in future be used to identify service user characteristics associated with different levels of continuity and therefore help target extra support to vulnerable groups. They may also be used as outcomes against which to test measures (in particular service configurations) deployed to improve continuity. It is unlikely that a model comprising seven factors would be used in routine services. As it presently stands, however, it may provide for clinicians a means of conceptualising continuity of care for mental health, along with a wideranging set of measures of continuity in its different facets, from which different aspects could be selected to reflect service priorities. The relative clinical importance of the seven factors 
remains to be tested against relevant clinical and social outcome measures. Further research should then identify the optimal continuity of care factors as the minimum necessary components of care for service users with chronic mental health problems.

This study was funded by a grant (SDO/13(d)2001) from the

National Co-ordinating Centre for NHS Service Delivery and Organisation R\&D (NCCSDO)

London School of Hygiene and Tropical Medicine

99 Gower Street,

London WC1E 6AA 


\section{Tables and Illustrations}

\section{Box 1: Multi-axial definition of continuity of care}

Generic (Freeman et al. 2000)

Experienced (experience of a coordinated and smooth progression of care from the user's point of view)

Flexible (to be flexible and adjust to the needs of the individual over time)

Cross-boundary (effective communication between professionals and services and with service users)

Information (excellent information transfer following the service user)

Longitudinal (care from as few professionals as possible, consistent with other needs)

Relational (to provide one or more named individual professionals with whom the user can establish and maintain a therapeutic relationship)

Mental health-specific (Freeman et al. 2002)

Long-term (uninterrupted care for as long as the service user requires it)

Contextual (care which should sustain a person's preferred social and personal relationship in the community and enhance quality of life) 


\begin{tabular}{|c|c|}
\hline \multicolumn{2}{|l|}{ Box 2: Continuity of care components } \\
\hline \multicolumn{2}{|l|}{$\begin{array}{l}\text { Type of continuity } \\
\text { Component }(\text { later omitted })^{1}\end{array}$} \\
\hline Experienced Continuity & Longitudinal continuity \\
\hline CONTINU-UM ${ }^{2}$ & Designated care coordinators $(\mathrm{CC})^{2}$ \\
\hline Flexible Continuity (Range of needs) & Designated psychiatrists (Psych) ${ }^{2}$ \\
\hline CAN Total number of needs ${ }^{2,3}$ & Non-medical input spread (number of different non-medical \\
\hline CAN Number of met needs ${ }^{2}$ & team members seen out of the total number of contacts with \\
\hline CAN Number of unmet needs ${ }^{2}$ & non-medical team members) \\
\hline CAN Total level of needs ${ }^{2,3}$ & Medical input spread (number of different medical team \\
\hline $\begin{array}{l}\text { CAN Total level of needs met by informal } \\
\text { carers }\end{array}$ & $\begin{array}{l}\text { members seen out of the total number of contacts with medical } \\
\text { team members) }\end{array}$ \\
\hline \multicolumn{2}{|l|}{ Proportion of needs met ${ }^{2}$} \\
\hline Flexible Continuity (Meeting changes in & Relational continuity \\
\hline clinical needs) & STAR total score-any professional ${ }^{2,4}$ \\
\hline Increased contacts in 3 months prior to user & \\
\hline deterioration $^{2}$ & Long-term continuity \\
\hline Increased contacts in 3 months prior to hospital & Average gap between face-to-face contacts ${ }^{3}$ \\
\hline admission & Gaps of 2 months or more \\
\hline Cross-boundary continuity & Longest gap between contacts ${ }^{3}$ \\
\hline Had a transition? & Gaps of (average gap $* 2+2$ weeks) \\
\hline Referred to other agency & Number of user-rated breaks in care $e^{2,3}$ \\
\hline Contacts with primary care professionals ${ }^{2}$ & Total number of face-to-face contacts \\
\hline Number of agencies used in previous year ${ }^{2}$ & Total number of phonecalls \\
\hline Information continuity & Saw known CMHT member when hospitalised ${ }^{2}$ \\
\hline Documented transition & Any user-rated breaks in care $?^{2}$ \\
\hline Proportion of letters sent by CMHT copied to & Contextual continuity \\
\hline user & Attendance at day care ${ }^{2}$ \\
\hline CPA copied to GP and user & Supported accommodation ${ }^{2}$ \\
\hline
\end{tabular}

1. Items in italics were subsequently dropped from the analysis, for reasons given in the text.

2. Information from the service user.

3. Variable reversed so that a high score indicates an assumed positive scenario: e.g. a high score for 'average gap between face-to-face contacts' would indicate short average gaps.

4. For users with no identified care coordinator (STAR-c rating), the STAR concerning the relationship with the psychiatrist (STAR-p) was used; where no psychiatrist was identified or rated, the STAR concerning the relationship with a third identified professional (STAR-o) was used, to maximise data. 


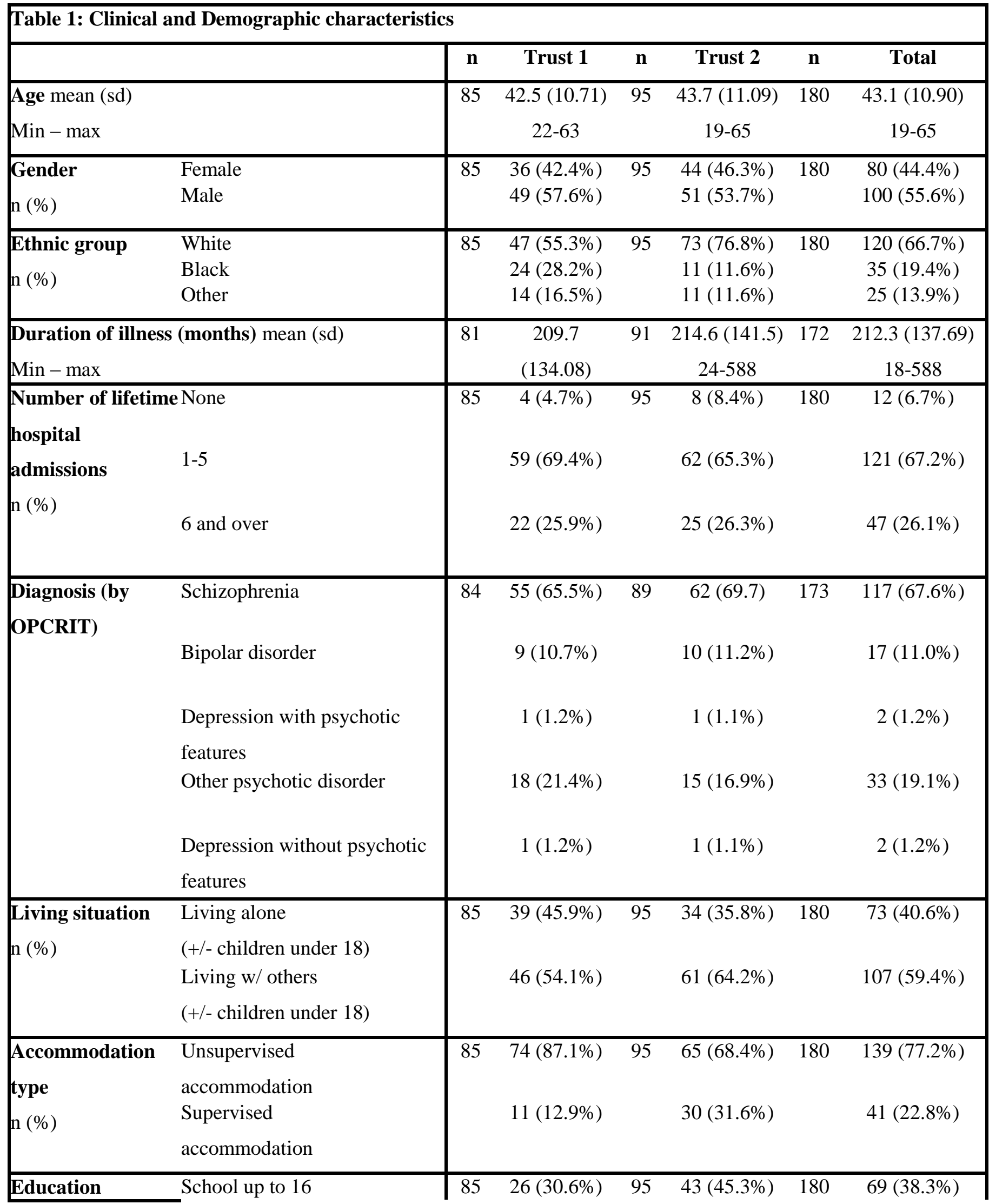




\begin{tabular}{|c|c|c|c|c|c|c|c|}
\hline $\mathrm{n}(\%)$ & School above 16 & & $59(69.4 \%)$ & & $52(54.7 \%)$ & & $111(61.7 \%)$ \\
\hline $\begin{array}{l}\text { Employment } \\
\text { Status }\end{array}$ & Paid employment $^{1}$ & 54 & $9(16.7 \%)$ & 83 & $9(10.8 \%)$ & 137 & $18(13.1 \%)$ \\
\hline $\ln (\%)$ & Unemployed or unpaid work ${ }^{2}$ & & $45(83.3 \%)$ & & $74(89.2 \%)$ & & $119(86.9 \%)$ \\
\hline
\end{tabular}

1. Includes full-time, part-time and sheltered work and self-employment.

2. Includes seeking work, unable to work, studying, retired or other. 


\begin{tabular}{|c|c|c|c|}
\hline \multicolumn{3}{|c|}{ Table 2: Continuity of care factors } & \multirow[b]{2}{*}{$\begin{array}{c}\% \text { of } \\
\text { Variance }\end{array}$} \\
\hline Factor & Items & $\begin{array}{l}\text { Description } \\
\text { (high score) }\end{array}$ & \\
\hline 1 & $\begin{array}{l}\text { CONTINU-UM } \\
\text { STAR total score-any professional } \\
\text { Proportion of needs met } \\
\text { Any user-rated breaks in care? (negative }{ }^{1} \text { ) }\end{array}$ & $\begin{array}{l}\text { Experience \& Relationship (experienced \& } \\
\text { relational continuity) } \\
\text { high experienced continuity, good therapeutic } \\
\text { relationship, a greater proportion of needs met } \\
\text { and not having a user-rated break in care }\end{array}$ & $12.5 \%$ \\
\hline 2 & $\begin{array}{l}\text { Average gap between face-to-face } \\
\text { contacts } \\
\text { Gaps of } 2 \text { months or more } \\
\text { Non-medical input spread }\end{array}$ & $\begin{array}{l}\text { Regularity (long-term / longitudinal continuity) } \\
\text { being seen more frequently by staff from fewer } \\
\text { different non-medical disciplines }\end{array}$ & $12.2 \%$ \\
\hline$\overline{3}$ & $\begin{array}{l}\text { CAN Total level of needs } \\
\text { CAN Number of met needs } \\
\text { CPA copied to GP and user }\end{array}$ & $\begin{array}{l}\text { Meeting Needs (flexible continuity) } \\
\text { high level of need, high number of met needs and } \\
\text { CPA copied to GP and user }\end{array}$ & $9.5 \%$ \\
\hline 4 & $\begin{array}{l}\text { Number of agencies used in previous year } \\
\text { Contacts with primary care professionals }\end{array}$ & $\begin{array}{l}\text { Consolidation (cross-boundary continuity) } \\
\text { having contact with fewer different agencies and } \\
\text { not seeing primary care professionals }\end{array}$ & $8.1 \%$ \\
\hline 5 & $\begin{array}{l}\text { Had a transition? } \\
\text { Documented transition }\end{array}$ & $\begin{array}{l}\text { Managed Transitions (cross-boundary } \\
\text { continuity) } \\
1=\text { no transition, } 0=\text { documented transition, } \\
-1=\text { undocumented transition }\end{array}$ & $7.3 \%$ \\
\hline 6 & $\begin{array}{l}\text { Designated care coordinators } \\
\text { Designated psychiatrists }^{\left(\text {negative }^{1} \text { ) }\right.} \\
\text { CAN Total level of needs met by } \\
\text { informal carers (reversed }{ }^{1} \text { ) }\end{array}$ & $\begin{array}{l}\text { Care Coordination (longitudinal continuity) } \\
\text { having a designated care coordinator, having no } \\
\text { psychiatrist or more than two and fewer needs } \\
\text { met by informal carers }\end{array}$ & $6.5 \%$ \\
\hline$\overline{7}$ & $\begin{array}{l}\text { Supported accommodation } \\
\text { Attendance at day centres or hospitals } \\
\text { Proportion of letters sent by CMHT } \\
\text { which were sent or copied to user }\end{array}$ & $\begin{array}{l}\text { Supported Living (contextual continuity) } \\
\text { living in supported accommodation, attending } \\
\text { day care and having more letters copied to the } \\
\text { user }\end{array}$ & $6.4 \%$ \\
\hline & & Total & $62.5 \%$ \\
\hline
\end{tabular}

1. 'Negative' indicates that the component loads negatively onto the factor, indicating an inverse relationship, while 'reversed' indicates that the variable was reverse-scored from the outset so that a high score would indicate a positive scenario. 


\begin{tabular}{|c|c|c|c|c|c|c|c|}
\hline \multicolumn{2}{|l|}{ Mean (sd) or $n(\%)$} & $\mathbf{n}$ & Trust 1 & $\mathbf{n}$ & Trust 2 & $\mathbf{n}$ & Total \\
\hline \multicolumn{8}{|c|}{ Factor 1: Experience \& Relationship } \\
\hline \multicolumn{2}{|l|}{ CONTINUUM Mean score (1-5) } & 78 & $3.5(.692)$ & 89 & $3.4(.818)$ & 167 & $\begin{array}{c}3.5(.764) \\
1.5-4.8\end{array}$ \\
\hline \multicolumn{2}{|c|}{$\begin{array}{l}\text { STAR Total score - Any professional } \\
(0-48)\end{array}$} & 83 & $37.6(8.68)$ & 81 & $35.4(9.26)$ & 164 & $\begin{array}{c}36.5(9.01) \\
6-48\end{array}$ \\
\hline CAN-Proportion of needs met & $\begin{array}{l}<65 \% \\
65-91 \% \\
>91 \%\end{array}$ & 84 & $\begin{array}{l}27(32.1 \%) \\
23(27.4 \%) \\
34(40.5 \%)\end{array}$ & 94 & $\begin{array}{l}32(34.0 \%) \\
26(27.7 \%) \\
36(38.3 \%)\end{array}$ & 178 & $\begin{array}{l}59(33.1 \%) \\
49(27.5 \%) \\
70(39.3 \%)\end{array}$ \\
\hline Any user-rated breaks in care & $\begin{array}{l}\text { Yes } \\
\text { No }\end{array}$ & 85 & $\begin{array}{c}3(3.5 \%) \\
82(96.5 \%)\end{array}$ & 93 & $\begin{array}{c}9(9.7 \%) \\
84(90.3 \%)\end{array}$ & 178 & $\begin{array}{c}12(6.7 \%) \\
166(93.3 \%)\end{array}$ \\
\hline \multicolumn{8}{|l|}{ Factor 2: Regularity } \\
\hline \multicolumn{2}{|c|}{$\begin{array}{l}\text { Average gap between face-to-face contacts } \\
\text { (days) }\end{array}$} & 83 & $22.2(12.46)$ & 83 & $67.6(44.47)$ & 166 & $\begin{array}{c}44.9(39.71) \\
4-206\end{array}$ \\
\hline Gaps of 2 months or more & $\begin{array}{l}\text { Yes } \\
\text { No }\end{array}$ & 84 & $\begin{array}{l}27(32.1 \%) \\
57(67.9 \%)\end{array}$ & 92 & $\begin{array}{l}77(83.7 \%) \\
15(16.3 \%)\end{array}$ & 176 & $\begin{array}{l}104(59.1 \%) \\
72(40.9 \%)\end{array}$ \\
\hline Non-medical input spread & $\begin{array}{l}=>50 \% \\
21-49 \% \\
=<20 \%\end{array}$ & 82 & $\begin{array}{c}5(6.1 \%) \\
6(7.3 \%) \\
71(86.6 \%)\end{array}$ & 40 & $\begin{array}{c}19(47.5 \%) \\
8(20.0 \%) \\
13(32.5 \%)\end{array}$ & 122 & $\begin{array}{l}24(19.7 \%) \\
14(11.5 \%) \\
84(68.9 \%)\end{array}$ \\
\hline \multicolumn{8}{|l|}{ Factor 3: Meeting Needs } \\
\hline \multicolumn{2}{|l|}{ CAN- Total level of needs (0-66) } & 84 & $8.2(4.56)$ & 94 & $8.7(5.15)$ & 178 & $\begin{array}{c}8.5(4.87) \\
1-23\end{array}$ \\
\hline \multicolumn{2}{|c|}{ CAN- Number of met needs $(0-22)$} & 84 & $4.3(2.11)$ & 94 & $4.4(2.51)$ & 178 & $\begin{array}{c}4.4(2.33) \\
0-12\end{array}$ \\
\hline CPA copied to GP and user & $\begin{array}{l}\text { No } \\
\text { To one } \\
\text { To both }\end{array}$ & 79 & $\begin{array}{c}9(11.4 \%) \\
35(41.2 \%) \\
35(44.3 \%)\end{array}$ & 68 & $\begin{array}{l}26(38.2 \%) \\
26(38.2 \%) \\
15(18.8 \%)\end{array}$ & 147 & $\begin{array}{l}35(23.8 \%) \\
61(41.5 \%) \\
51(34.7 \%)\end{array}$ \\
\hline \multicolumn{8}{|l|}{ Factor 4: Consolidation } \\
\hline $\begin{array}{l}\text { Number of agencies used in the } \\
\text { Previous year }\end{array}$ & & 72 & $5.2(2.71)$ & 79 & $4.9(3.05)$ & 151 & $\begin{array}{c}5.1(2.89) \\
1-16\end{array}$ \\
\hline Contact with primary care & Yes & 72 & $52(72.2 \%)$ & 79 & $35(44.3 \%)$ & 151 & $87(57.6)$ \\
\hline
\end{tabular}




\begin{tabular}{|c|c|c|c|c|c|c|c|c|}
\hline \multicolumn{2}{|l|}{ professionals } & \multirow[t]{2}{*}{ No } & & \multicolumn{2}{|l|}{$20(27.8 \%)$} & \multicolumn{2}{|l|}{$44(55.7 \%)$} & \multirow[t]{2}{*}{$64(42.4)$} \\
\hline \multicolumn{7}{|c|}{ Factor 5: Managed Transitions } & & \\
\hline \multirow{2}{*}{\multicolumn{2}{|c|}{ Had a transition? }} & Yes & 82 & $33(40.2 \%)$ & 92 & $21(22.8 \%)$ & 174 & $54(31.0 \%)$ \\
\hline & & No & & $49(59.8 \%)$ & & $71(77.2 \%)$ & & $120(69.0 \%)$ \\
\hline \multirow[t]{3}{*}{ Documented transition? } & \multicolumn{2}{|c|}{$\begin{array}{l}\text { Documented } \\
\text { transition }\end{array}$} & 82 & $7(8.5 \%)$ & 92 & $10(10.9 \%)$ & 174 & $17(9.8 \%)$ \\
\hline & \multicolumn{2}{|c|}{$\begin{array}{l}\text { No relevant } \\
\text { transition }\end{array}$} & & $49(59.8 \%)$ & & $71(77.1 \%)$ & & $120(69.0 \%)$ \\
\hline & \multicolumn{2}{|c|}{$\begin{array}{l}\text { Undocumented } \\
\text { transition }\end{array}$} & & $26(31.7 \%)$ & & $11(12.0 \%)$ & & $37(21.3 \%)$ \\
\hline \multicolumn{9}{|c|}{ Factor 6: Care Coordination } \\
\hline \multirow{2}{*}{\multicolumn{2}{|c|}{$\begin{array}{l}\text { Number of designated care } \\
\text { coordinators }\end{array}$}} & 0 or $3+$ & 85 & $9(10.6 \%)$ & 90 & $24(26.7 \%)$ & 175 & $33(18.9 \%)$ \\
\hline & & 1 or 2 & & $76(89.4 \%)$ & & $66(73.3 \%)$ & & $142(81.1 \%)$ \\
\hline \multirow{2}{*}{\multicolumn{2}{|c|}{ Number of designated psychiatrists }} & 0 or $3+$ & 85 & $18(21.2 \%)$ & 95 & $20(21.1 \%)$ & 180 & $38(21.1 \%)$ \\
\hline & & 1 or 2 & & $67(78.8 \%)$ & & $75(78.9 \%)$ & & $142(78.9 \%)$ \\
\hline \multicolumn{3}{|c|}{$\begin{array}{l}\text { CAN- Total level of needs met by } \\
\text { informal carers }(0-22)\end{array}$} & 84 & $3.6(4.18)$ & 94 & $3.2(3.96)$ & 178 & $\begin{array}{c}3.4(4.06) \\
0-21\end{array}$ \\
\hline \multicolumn{9}{|c|}{ Factor 7: Supported Living } \\
\hline \multirow{2}{*}{\multicolumn{2}{|c|}{ Supported accommodation }} & Yes & 72 & $4(5.6 \%)$ & 77 & $15(19.5 \%)$ & 149 & $19(12.8 \%)$ \\
\hline & & No & & $68(94.4 \%)$ & & $62(80.5 \%)$ & & $130(87.2 \%)$ \\
\hline \multirow{2}{*}{\multicolumn{2}{|c|}{$\begin{array}{l}\text { Attendance at day centres or } \\
\text { hospitals }\end{array}$}} & Yes & 72 & $18(25.0 \%)$ & 77 & $12(15.6 \%)$ & 149 & $30(20.1 \%)$ \\
\hline & & No & & $54(75.0 \%)$ & & $65(84.4 \%)$ & & $119(79.9 \%)$ \\
\hline \multirow{3}{*}{\multicolumn{2}{|c|}{$\begin{array}{l}\text { Proportion of letters sent by CMHT } \\
\text { sent or copied to user }\end{array}$}} & None & 79 & $38(48.1 \%)$ & 80 & $50(62.5 \%)$ & 159 & $88(55.3 \%)$ \\
\hline & & $<=50 \%$ & & $10(12.7 \%)$ & & $15(18.8 \%)$ & & $25(15.7 \%)$ \\
\hline & & $>50 \%$ & & $31(39.2 \%)$ & & $15(18.8 \%)$ & & $46(28.9 \%)$ \\
\hline
\end{tabular}




\section{References}

Adair CE, McDougall GM, Beckie A, Joyce A, Mitton C, Wild CT, Gordon A, Costigan N (2003). History and measurement of continuity of care in mental health services and evidence of its role in outcomes. Psychiatric Services 54, 1351-1356.

Adair CE, McDougall GM, Mitton CR, Joyce AS, Wild TC, Gordon A, Costigan N, Kowalsky L, Pasmeny G, Beckie A (2005). Continuity of care and health outcomes among persons with severe mental illness. Psychiatric Services, 56, 1061-1069.

Bachrach L (1981). Continuity of care for chronic mental users: a conceptual analysis. American Journal of Psychiatry, 138, 1449-1455.

\section{Bindman J, Johnson S, Wright S, Szmukler G, Bebbington P, Kuipers E, Thornicroft G} (1997). Integration between primary and secondary services in the care of the severely mentally ill: patients' and general practitioners' views. British Journal of Psychiatry 171, 169-174.

Cook RI, Render M, Woods DD (2000). Gaps in the continuity of care and progress on patient safety. British Medical Journal, 320, 791-794.

Crawford M, Jonge E, Freeman G, Weaver T (2004). Providing continuity of care for people with severe mental illness. Social Psychiatry and Psychiatric Epidemiology, 39, 265272.

Department of Health (1995). Building Bridges: A guide to arrangements for inter-agency working for the care and protection of severely mentally ill people. Department of Health: London.

Department of Health (1990). The Care Programme Approach for people with a mental illness referred to the Special Psychiatric Services Joint Health/Social Services Circular HC (90) 23/LASS (90) 11. Department of Health: London.

Department of Health (2001). Mental Health Policy Implementation Guide. Department of Health: London.

Freeman G, Shepperd S, Robinson I, Ehrich K, Richards S (2000). Continuity of Care: Report of a Scoping Exercise for the SDO Programme of NHS R\&D. National Coordinating Centre for Service Delivery and Organisation: London.

Freeman G, Weaver T, Low J, de Jonge E, Crawford M (2002). Promoting Continuity of Care for People with Severe Mental Illness whose needs span primary, secondary and social care. National Coordinating Centre for Service Delivery and Organisation: London. 
Haggerty JL, Reid RJ, Freeman GK, Starfield BH, Adair CE, McKendry R (2003). Continuity of care: a multidisciplinary review. British Medical Journal, 327, 12191221.

Heslop L, Elsom S, Parker N. (2000). Improving continuity of care across psychiatric and emergency services: combining patient data within a participatory action research framework. Journal of Advanced Nursing, 31, 135-143.

Johnson S, Prosser D, Bindman J, Szmukler G (1997). Continuity of care for the severely mentally ill: concepts and measures. Social Psychiatry and Psychiatric Epidemiology, 32, $137-142$.

Joyce A, Wild T, Adair C, McDougall G, Gordon A, Costigan N, Beckie A, Kowalsky L, Pasmeny G, Barnes F (2004) Continuity of care in mental health services: toward clarifying the construct. Canadian Journal of Psychiatry, 49, 539-550.

Kaiser HF (1974). Index of Factorial Simplicity. Psychometrika, 39, 31-36.

Kopelowicz A, Wallace C, Zarate R. (1998). Teaching psychiatric inpatients to re-enter the community: a brief method of improving the continuity of care. Psychiatric Services, 49, 1313-1316.

McGuffin P, Farmer A, Harvey I (1991). A polydiagnostic application of operational criteria in studies of psychotic illness. Development and reliability of the OPCRIT system. Archives of General Psychiatry, 48, 764-770.

McGuire-Snieckus R, McCabe R, Catty J, Priebe S (2006). A new scale to assess the therapeutic relationship in community mental health care: STAR. Psychological Medicine, 37, 85-95.

Mitton CR, Adair CE, McDougall GM, Marcouz G (2005). Continuity of care and health care costs among persons with severe mental illness. Psychiatric Services, 56, 10701076.

Mueser KT, Bond GR, Drake RE, Resnick SG (1998). Models of community care for severe mental illness: a review of research on case management. Schizophrenia Bulletin, 24, $37-74$.

Nutting PA, Goodwin MA, Flocke SA, Zyzanski SJ, Stange KC (2003). Continuity of primary care: to whom does it matter and when? Annals of Family Medicine, 1, 149155.

Phelan M, Slade M, Thornicroft G, Dunn G, Holloway F, Wykes T, Strathdee G, Loftus L, McCrone P, Hayward P (1995). The Camberwell Assessment of Need: the validity and reliability of an instrument to assess the needs of people with severe mental illness. British Journal of Psychiatry, 167, 589-595. 
Reid R, Haggerty J, McKendry R (2002). Defusing the Confusion: Concepts and Measures of Continuity of Healthcare. Final Report. Canadian Health Services Research Foundation (CHSRF): Ottawa, Canada.

Rose D, Wykes T, Sweeney A, Leese M, Clement S, Jones IR, Catty J, Burns T (submitted). Developing a user-generated measure of continuity of care. Acta Psychiatrica Scandinavica.

Sytema S, Burgess P (1999). Continuity of care and readmission in two service systems: a comparative Victorian and Groningen case-register study. Acta Psychiatrica Scandinavica, 100, 212-219.

Sytema S, Micciolo R, Tansella M (1997). Continuity of care for patients with schizophrenia and related disorders: a comparative South-Verona and Groningen case-register study. Psychological Medicine, 27, 1355-1362.

Tessler RC (1987). Continuity of care and client outcome. Psychosocial Rehabilitation Journal, 11, 39-53.

Ware NC, Dickey B, Tugenberg T, McHorney CA (2003) CONNECT: a measure of continuity of care in mental health services. Mental Health Services Research, 5, 209221. 